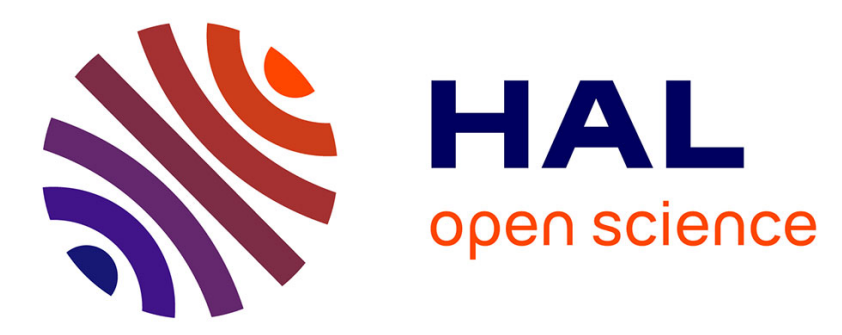

\title{
Polarization-dependent optical band gap energy of aligned semiconducting titanium oxide nanowire deposits
}

Merve Taner Camci, Matthias Pauly, Christophe Lefevre, Corinne Bouillet, Mounir Maaloum, Gero Decher, David Martel

\section{- To cite this version:}

Merve Taner Camci, Matthias Pauly, Christophe Lefevre, Corinne Bouillet, Mounir Maaloum, et al.. Polarization-dependent optical band gap energy of aligned semiconducting titanium oxide nanowire deposits. Nanoscale, 2021, 13 (19), pp.8958-8965. 10.1039/d1nr01236c . hal-03369981

\section{HAL Id: hal-03369981 \\ https://hal.science/hal-03369981}

Submitted on 26 Oct 2021

HAL is a multi-disciplinary open access archive for the deposit and dissemination of scientific research documents, whether they are published or not. The documents may come from teaching and research institutions in France or abroad, or from public or private research centers.
L'archive ouverte pluridisciplinaire HAL, est destinée au dépôt et à la diffusion de documents scientifiques de niveau recherche, publiés ou non, émanant des établissements d'enseignement et de recherche français ou étrangers, des laboratoires publics ou privés. 


\title{
Polarization-dependent optical band gap energy of aligned semiconducting titanium oxide nanowire deposits
}

\author{
Merve Taner Camci, ${ }^{a}$ Matthias Pauly, ${ }^{a}$ Christophe Lefevre, ${ }^{b}$ Corinne Bouillet, ${ }^{b}$ Mounir Maaloum, ${ }^{a}$
} Gero Decher ${ }^{\mathrm{a}, \mathrm{c}, \mathrm{d}, \mathrm{e} *}$ and David Martel ${ }^{\mathrm{a} *}$

\begin{abstract}
aUniversité de Strasbourg, CNRS, Institut Charles Sadron (ICS), UPR 22, F-67000 Strasbourg, France. E-mail: decher@unistra.fr, david.martel@ics-cnrs.unistra.fr

bUniversité de Strasbourg, CNRS, Institut de Physique et de Chimie des Matériaux de Strasbourg (IPCMS), UMR 7504, F-67000 Strasbourg, France

${ }^{c}$ Faculté de Chimie, Université de Strasbourg, 1 rue Blaise Pascal, F-67008 Strasbourg, France

${ }^{\mathrm{d}}$ International Center for Frontier Research in Chemistry, 8 allée Gaspard Monge, F-67083 Strasbourg, France

e International Center for Materials Nanoarchitectonics, 1-1 Namiki Tsukuba,
\end{abstract}

Electronic Supplementary Information (ESI) available: [determination of the optical band gap, the influence of the surface coverage and reflection and additional experimental results are available in the Supporting Information]. See DOI: $10.1039 / \mathrm{d} 1 \mathrm{nr} 01236 \mathrm{c}$

\begin{abstract}
Thin deposits of aligned semiconducting titanium oxide and of zinc oxide nanowires are prepared by grazing incidence spraying on transparent substrates. By measuring the transmittance of linearly polarized light of these anisotropic assemblies as compared to that of randomly oriented nanowires and of spherical nanoparticles, we find that titanium oxide nanowires exhibit an orientationdependent variation of the apparent optical band gap energy at room temperature ( $>100 \mathrm{meV}$ ), depending on the direction of the polarization of the light with respect to the direction of alignment of the nanowires.
\end{abstract}

\section{Introduction}

Anisotropic nano-objects such as nanorods, nanowires (NWs), nanotubes (1D) or thin films (2D) have attracted attention for a long time on account of their size-dependent properties, which differ from those of the bulk state. ${ }^{1}$ These novel properties are potentially interesting for applications in various areas like electronics, ${ }^{2}$ optoelectronics, ${ }^{3}$ mechanics ${ }^{4}$ or photo-catalysis. ${ }^{5}$ Notably, the opto-electronic properties of semiconductors are dictated by their electronic band structure, which has been shown to depend on the dimension and composition for 2D films and 1D nanorods/nanowires, leading to particular characteristics. ${ }^{6} \mathrm{~A}$ large anisotropy of the photoluminescence intensity has already been measured at room temperature, ${ }^{7}$ but such an anisotropy should not be expected for the band gap energy at ambient temperature. Although, calculated band diagrams show differences in the gap energy depending on the polarization of the light, these differences, in the range of a few tens of $\mathrm{meV},{ }^{8,9}$ vanishes at room temperature. Quantum confinement, which has been observed in NWs of smaller diameter, could also lead to variations in the energy gap. ${ }^{9}$ Numerous strategies enabling the in-plane alignment of 1D nano-objects have been developed, ${ }^{10}$ but to fulfil the various requirements for a specific application by means of a simple and efficient approach is still a challenge. Such a method should be as versatile as possible to allow a wide variety of 1D materials to be deposited on a largescale at low cost, with a density ranging from low to high coverage and precise control of the orientation of the nano-objects. Besides the top-down techniques, e.g., e-beam lithography, the development of bottom-up assembly approaches is quite promising because it should allow one to build up more complex architectures as compared to the top-down structures. ${ }^{11}$ The orientation in bottom-up assemblies can be induced by electric or magnetic fields in materials sensitive to these physical forces, or by oriented growth as in vapor-liquid-solid or vapor-solid methods. Lithographic or fluid flow procedures are also employed but would seem limited in terms of the materials which can be deposited and the geometric versatility and/or are tedious to implement. ${ }^{6}$ Assemblies of aligned 1D objects can also be obtained by the well-known Langmuir-Blodgett technique, ${ }^{12}$ although the 
alignment may be perturbed during the transfer of the compressed objects from the liquid-air interface to the substrate.

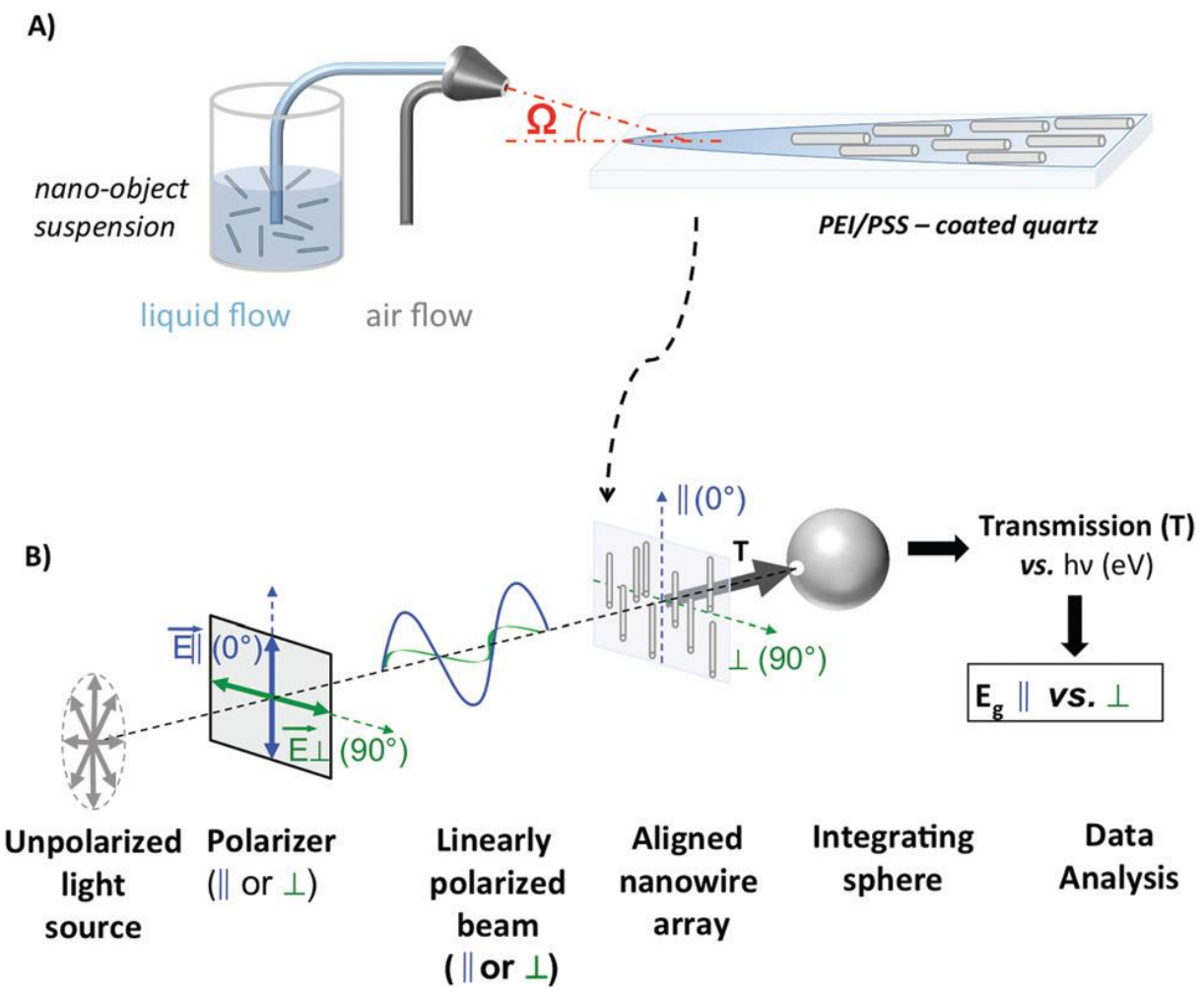

Fig. 1 Schematic representation of A) Grazing Incidence Spraying (GIS) and B) measurement of the transmission of linearly polarized light through an oriented array of NWs.

Our team has recently introduced a new method allowing the alignment of 1D objects through grazing incidence spraying (GIS). ${ }^{13}$ This technique relies on the shear force induced by low-angle spraying of a suspension of anisotropic objects onto a receiving substrate and it may be easily combined with other assembly processes ${ }^{14}$ to produce well-ordered thin films of large-area (Fig. 1A). This approach has already demonstrated its versatility and has been applied to metallic wires ${ }^{13,15,16}$ and organic microfibrils. ${ }^{17}$ In this study, we extended the use of GIS to semiconductor nanowires of titanium $\left(\mathrm{Ti}^{\mathrm{iV}}\right)$ oxide $^{\ddagger}$ and zinc oxide $(\mathrm{ZnO})$. The oriented films were prepared by spraying the nano-object suspensions at a low angle onto a quartz substrate previously coated with poly(ethyleneimine) (PEI) and poly(sodium 4-styrenesulfonate) (PSS). This led to a submonolayer oriented thin films of the NWs, as shown by AFM (Fig. 2A). Non-oriented films of the same nano-objects were prepared by drop casting (DC) of the nano-object suspensions onto a similar functionalized quartz substrate. As a control mimicking as closely as possible the structure of the oriented NW samples, spherical titanium oxide $\left(\mathrm{TiO}_{2}\right)$ nanoparticles (NPs) were deposited on similar substrates using GIS or DC, although obviously the thin films obtained were isotropic. In this work, we investigated on a macroscopic scale the optical properties of arrays of aligned NWs with respect to light polarized parallel $\left(0^{\circ}\right)$ and perpendicular $\left(90^{\circ}\right)$ to the long axis of the NWs (Fig. 1B). Thus, we measured the transmittance of linearly polarized light through arrays of oriented zinc oxide $(\mathrm{ZnO})$ and titanium $\left(\mathrm{Ti}^{\mathrm{iV}}\right)$ oxide nanowires. In addition to the polarization-dependent transmission spectra of oriented thin films, we observed a systematic difference in the apparent band gap energy $\Delta \mathrm{Eg}\left(90^{\circ}-0^{\circ}\right)$ of $>100 \mathrm{meV}$, but only for the $\mathrm{Ti}^{\mathrm{iV}}$ oxide and not for the ZnO NWs.

\footnotetext{
‡ Note that throughout the whole manuscript, we do not refer to "titanium oxide" as being conventional $\mathrm{TiO}_{2}$ "titania". Instead, as detailed in the discussion of Fig. 4, the "titanium oxide" refers to a Tilv mixed-phase material.
} 


\section{Experimental}

\section{Materials}

Titanium oxide (TilV) and zinc oxide ( $\mathrm{ZnO}$ ) nanowires (NWs) were purchased from Sigma-Aldrich (France) with the CAS number 13463-67-7 and 1314-13-2, respectively. $\mathrm{TiO}_{2}$ nanoparticles (P25) were gently provided by Evonik (Germany). Branched poly(ethyleneimine) (PEI) solution (50 wt\% in $\mathrm{H}_{2} \mathrm{O}$ ) with an average $\overline{M_{W}}=750000 \mathrm{~g} \cdot \mathrm{mol}^{-1}$ and poly(sodium 4-styrenesulfonate) (PSS) with an average $\overline{M_{W}}$ $=70000 \mathrm{~g} \cdot \mathrm{mol}^{-1}$ were purchased from Sigma-Aldrich. Quartz substrates $(1.2 \mathrm{~cm} \times 3.1 \mathrm{~cm})$ were purchase from M\&B Thuet (France). MilliQ water (resistivity of $18.2 \mathrm{M} \Omega \cdot \mathrm{cm}$, Milli-Q Gradient system, Millipore) is used in all experiments.

\section{Nano-objects deposition by Drop casting (DC) or oriented by Grazing Incidence Spraying (GIS)}

All quartz substrates $(\mathrm{Q})$ were cleaned by $\mathrm{N} 2$ flow prior to 10 min ultrasonication in ethanol followed by water rinsing and N2 drying before plasma activation (Harrick Plasma, Ithaca, NY, USA) at high intensity for $3 \mathrm{~min}$. A layer of PEI and PSS were successively deposited by the Layer-by-Layer (LbL) deposition: PEI ( $2.5 \mathrm{mg} \cdot \mathrm{mL}^{-1}$ in $\left.\mathrm{H}_{2} \mathrm{O}\right)$ and PSS $\left(2.5 \mathrm{mg} \cdot \mathrm{mL}^{-1}\right.$ in nitric acid $\left(\mathrm{HNO}_{3}, \mathrm{pH}=2.5\right)$ ) layers were sprayed by manual air-pump spray bottles for $10 \mathrm{~s}$. The clean quartz slides were fixed vertically and spraying was applied perpendicularly to the quartz surface. After the deposition of each polyelectrolyte layer (PEI and PSS), a rinsing step was applied with Milli-Q water for $10 \mathrm{~s}$ to remove weakly adsorbed materials (Fig. S1). This results in a negatively charged substrate, on which the positively charged NPs and NWs were deposited. ${ }^{18}$ NPs and NWs were deposited by Grazing Incidence Spraying (GIS) on Quartz/PEI/PSS substrate, using a homemade spraying system equipped with gas flow controllers, liquid-handling pumps and 2-fluid nozzles (internal diameter $1.02 \mathrm{~mm}$, Aztek airbrush, Testors USA). The nozzle was placed in contact with one end of the substrate and the angle between the spray cone central axis and the substrate was around $30-40^{\circ} \mathrm{C}$. GIS depositions were followed by a rinsing step with Milli-Q water and the substrates were dried under N2 flow. The same suspensions were also deposited by Drop Casting followed by drying under ambient atmosphere one drop of the prepared suspension onto a Quartz/PEI/PSS substrate. The suspensions composition and spraying conditions are given below. In contrast of the usual conditions, ${ }^{19}$ Diluted suspensions have to be employed to avoid aggregation of the NWs, which limits the coverage that can be attained by GIS.

\section{$\mathrm{Ti}^{\mathrm{IV}}$ oxide NWs}

TilV oxide NWs (diameter $\approx 100 \mathrm{~nm}$, length $\approx 10 \mu \mathrm{m}$ ) were dispersed in $\mathrm{pH}=2.5 \mathrm{HNO}_{3}$ solution $(0.034$ $\mathrm{mg} \cdot \mathrm{mL}^{-1}$ ) and sonicated in an ultrasonication bath for $30 \mathrm{~min}$. The resulting suspension was allowed to settle for $30 \mathrm{~min}$ prior to Grazing Incidence Spraying (GIS). Tilv oxide NWs suspension was sprayed from the supernatant for $900 \mathrm{~s}$. The liquid flow rate was set to $1 \mathrm{~mL} \cdot \mathrm{min}^{-1}$ and the airflow to $15 \mathrm{~L} \cdot \mathrm{min}^{-1}$.

\section{ZnO NWs}

$\mathrm{ZnO} N W$ s (diameter $\approx 90 \mathrm{~nm}$, length $\approx 10 \mu \mathrm{m}$ ) were dispersed in Milli-Q water $\left(0.2 \mathrm{mg} \cdot \mathrm{mL}^{-1}\right.$ ) and sonicated in an ultrasonication bath for $30 \mathrm{~min}$. The resulting suspension was allowed to settle for 30 min prior to carrying out GIS. ZnO suspension was sprayed from the supernatant for $300 \mathrm{~s}$. The liquid flow rate was set to $2 \mathrm{~mL} \cdot \mathrm{min}-1$ and the airflow to $30 \mathrm{~L} \cdot \mathrm{min}^{-1}$.

\section{$\mathrm{TiO}_{2} \mathrm{NPs}$}

As reference particles without anisotropic shape titanium nanoparticles were used. GIS and DC were also applied to the NPs to keep the sample preparation conditions as close as possible for all nanoobjects. $2 \mathrm{~g}$ of Aeroxide ${ }^{\circledR} \mathrm{P}_{2} 5 \mathrm{TiO}_{2} \mathrm{NPs}$ were added to $80 \mathrm{~mL}$ of a pH $=2.5 \mathrm{HNO}_{3}$ solution and stirred for $1 \mathrm{~h}$. The suspension was sonicated using a tip-sonicator (Bioblock Scientific VibraCell 75042) with a power of $300 \mathrm{~W}$ for $25 \mathrm{~min}$ in order to prevent as much aggregation as possible. The suspension was cooled down to room temperature and centrifuged at $3700 \mathrm{rpm}$ for $15 \mathrm{~min}$ and the supernatant was collected for obtaining the smallest possible $\mathrm{TiO}_{2} \mathrm{NPs}$ aggregates. The $\mathrm{TiO}_{2} \mathrm{NP}$ suspension was sprayed for $200 \mathrm{~s}$. The liquid flow rate was set to $1.5 \mathrm{~mL} \cdot \mathrm{min}^{-1}$ and the airflow to $30 \mathrm{~L} \cdot \mathrm{min}^{-1}$. 


\section{AFM Measurements}

Atomic force microscopy (AFM) images were obtained by scanning the samples using an AFM Dimension Icon (Bruker) operated in Peak-Force tapping mode. During which the cantilever is oscillated in a similar fashion as it is in tapping mode, but far below the resonance frequency. Each time the tip and the sample are brought closer, a force is measured. These forces can be controlled at levels much lower than in contact mode and even lower than tapping mode allowing operation on the most delicate soft samples, as is the case here. Ultra-sharp silicon tip on nitride lever were used (Bruker, ScanAsyst with spring constant of $0.4 \mathrm{~N} \cdot \mathrm{m}-1$ ). During AFM imaging, the force was reduced in order to avoid dragging of molecules by the tip. All analyses of the images were conducted with the supplier's integrated software.

\section{TEM Measurements}

Transmission Electron Microscopy (TEM) and Energy Dispersive Spectroscopy (EDS) in Scanning Transmission Electronic Microscopy (STEM) measurements were performed using JEOL 2100FCs, operating at $200 \mathrm{kV}$, with a $0.2 \mathrm{~nm}$ point to point resolution.

\section{X-Ray Diffraction}

X-ray diffraction was performed with a Rigaku Smart Lab diffractometer equipped with a rotating copper anode $(\lambda \mathrm{Ka} \mathrm{Cu}=1.54056 \AA$ A).

\section{Optical Measurements}

The optical measurements were performed on a Cary 5000 (Agilent) UV-visible-Near Infrared spectrometer in double beam configuration with an integrating sphere (Internal Diffuse Reflectance Accessory DRA 2500). The samples are measured through a $5 \mathrm{~mm}$ diameter aperture fixed on a homemade sample holder so that the position of each sample is the same for all measurements. The transmittance of a blank quartz substrate is taken as reference. As the light beam in a Cary 5000 spectrometer is slightly polarized by the monochromators, a Hanle Wedge Depolarizers (B. Halle) was placed in front of the sample for the non-polarized transmittance and reflectance measurements, while a Glan-Taylor polarizer was used for the polarized light measurements. Transmission spectra are recorded in the range of $250 \mathrm{~nm}$ to $800 \mathrm{~nm}$, by collecting the transmitted light with the cap in "Sposition" (i.e. the angle of the direct beam is $3^{\circ} 20$ min with the back of the integrating sphere), allowing the integrating sphere to fully capture the transmitted light and to measure both the specular and diffuse components of the reflected light.

\section{Orientation Analysis}

The orientation of the NWs of the AFM images was performed with the OrientationJ-plugin ${ }^{20}$ developed for ImageJ. The local structure tensor in the local neighborhood of each pixel of the original images is computed, which allows defining a local orientation direction for each pixel with a certain coherency and energy value. The orientation distribution is calculated from the total number of pixels excluding the pixels that have coherency and energy values lower than $15 \%$ (i.e. pixels corresponding to the background or to edges and corners on which the orientation is not well-defined).

\section{Results and Discussion}

Using UV-Vis transmission spectroscopy, we determined the optical gap energy (Eg) of these objects when deposited as non-oriented or as highly oriented thin films (Fig. 1B). For each architecture, the Eg values were obtained using non-polarized and polarized light, the electric field being parallel $(E \|)$ or perpendicular $(E \perp)$ to the long axis of the wires in the oriented arrays. The orientation of the light polarization was chosen

arbitrarily for isotropic samples. Similar reference measurements were performed on thin films of spherical $\mathrm{TiO}_{2}$ nanoparticles (isotropic-shaped objects). The AFM images of the oriented thin films were analyzed using Orientation J, a plugin for the Image J program, which measures the orientation on a 
pixel scale according to its environment. The distribution of the orientation over the whole image can be extracted and the 2D nematic order parameter S2D may be calculated from this distribution using the Eq. 1:

$\mathrm{S}_{2 \mathrm{D}}=\left\langle 2 \cos ^{2} \phi-1\right\rangle \quad$ (1)

where $\phi$ is the angular deviation from the main orientation direction and the brackets denote an average over the entire picture. $S_{2 D}$ can be used to assess the quality of the orientation of the deposit, a value of 0 corresponding to a non-oriented array and a value of 1 to a perfectly aligned set of nanowires. The narrow angular distribution and high S2D values $\left(0.88\right.$ and $0.93 \mathrm{for} \mathrm{ZnO}$ and $\mathrm{Ti}^{\mathrm{iv}}$ oxide NWs, respectively) indicate that the NWs were highly oriented (Fig. 2C).

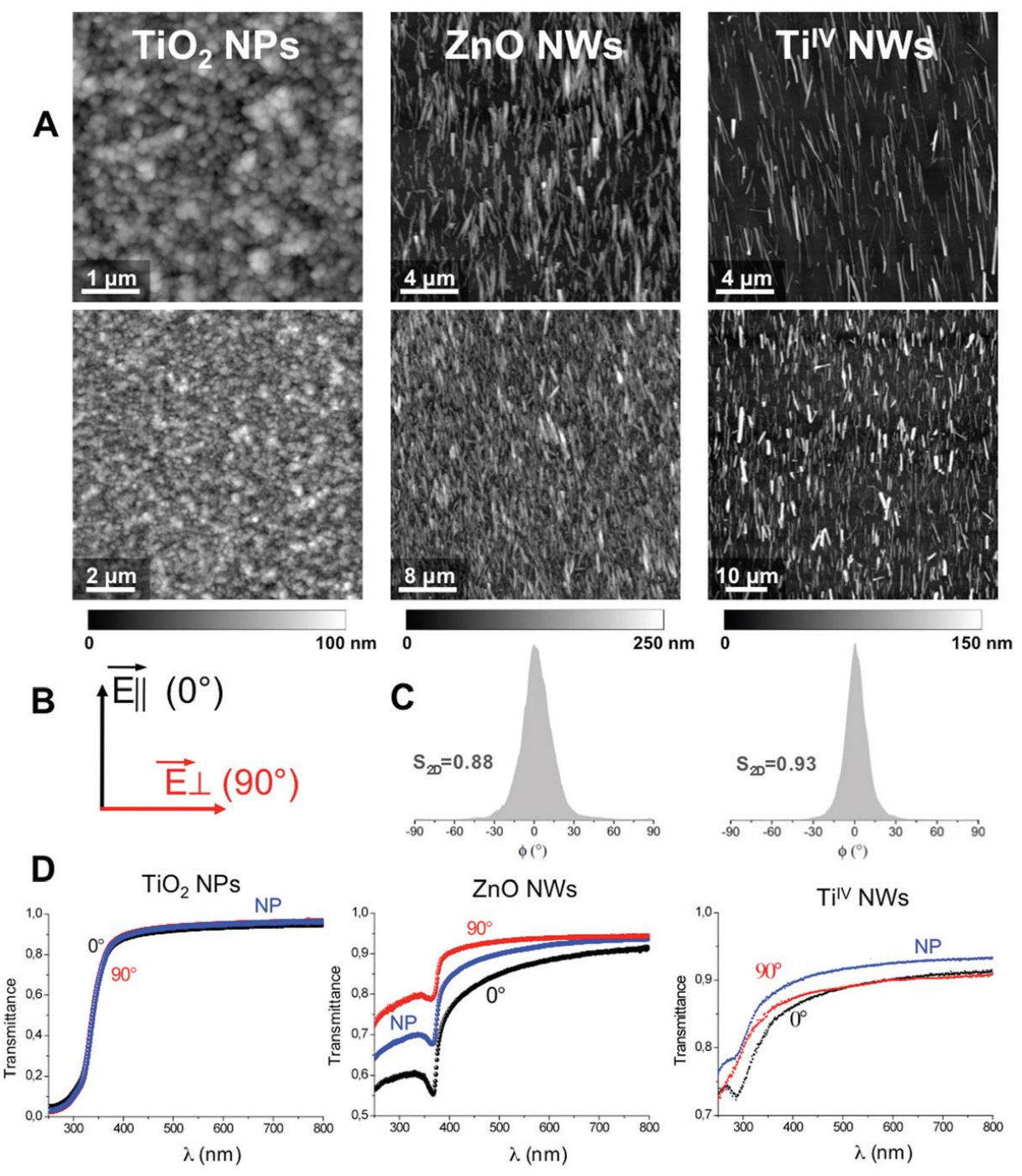

Fig. 2 (A) AFM images at two different magnifications of $\mathrm{TiO}_{2} \mathrm{NPS}$ and aligned $\mathrm{ZnO} \mathrm{NWs}$ and $\mathrm{Ti}^{\prime \mathrm{V}}$ oxide NWs deposited on quartz substrates by GIS. (B) Directions of the electric field vectors of the polarized light. (C) Orientation distributions and corresponding 2D order parameters (S2D) for the thin films of aligned ZnO NWs and $\mathrm{Ti}^{\mathrm{IV}}$ oxide NWs (回 is angular deviation). (D) Transmission spectra obtained with non-polarized light and light polarized perpendicular $\left(E \perp\left(90^{\circ}\right)\right.$ and parallel $\left(E \|\left(0^{\circ}\right)\right)$ to the orientation of the NWs ( $\lambda$ the wavelength in nanometer).

A conventional approach (section II of the ESI†) was used to determine the optical band gaps. Briefly, we measured the transmittance using an integrating sphere with non-polarized incident light or light 
polarized at $0^{\circ}$ or $90^{\circ}$ with respect to the direction of the long axis of the NWs (Fig. 2B). As expected, the transmittance of the isotropic thin films of spherical $\mathrm{TiO}_{2} \mathrm{NPs}$ and the drop-cast NWs (Fig. 2D and Fig. $\mathrm{S} 15-\mathrm{S} 17^{+}$) did not depend on the light polarization, whereas the transmittance of the films of oriented $\mathrm{ZnO}$ and TilV oxide NWs was lower when the light was polarized along the orientation direction. In each case, we determined the optical gap using two approaches, ${ }^{21}$ a simple model (eqn (2)) and a Tauc plot (eqn (3)):

$\alpha_{h v}=B\left(h v-E_{g}\right)^{p}$

or

$\alpha_{h v} h v=B\left(h v-E_{g}\right)^{p}$

where $B$ is a constant, and $p$ is linked to the electronic transition mechanism (a direct or indirect allowed transition corresponding to $p=1 / 2$ or $p=2$ respectively) and $h v$ is the incident light energy. Although the absorption coefficient $\alpha(h v)$ cannot be extracted from the transmittance as the thickness is undefined for a sub-monolayer thin film, an arbitrary value of the thickness may be assumed which will not affect the value of the band gap energy $E_{g}$, (section II of the ESI ${ }^{\dagger}$ ). Consequently, this quantity was denoted as $\alpha^{\prime}$ which is proportional to the absorption coefficient. In addition, the contribution of varying coverage and of reflection were taken into account (sections III and IV of the ESI') and our analysis suggests that such models seem to be viable for determining the optical gap energy with reasonable accuracy.

Fig. 3 shows the values of $E_{g}$ for several thin films of non-oriented and oriented $\mathrm{Ti}^{\mathrm{iv}}$ oxide NWs, determined using the Tauc model (eqn (3)) from the transmission spectra measured with light polarized at $0^{\circ}$ and $90^{\circ}$ and with non-polarized light, as well as the differences in the value of the energy gap $\Delta \mathrm{E}_{\mathrm{g}}\left(90^{\circ}-0^{\circ}\right)$. The complete results obtained for spherical $\mathrm{TiO}_{2} \mathrm{NPs}$ and $\mathrm{ZnO}$ and $\mathrm{Ti}^{\mathrm{IV}}$ oxide NWs, according to eqn (2) and (3), are presented in the ESI (Fig. S18+). As the $\mathrm{E}_{\mathrm{g}}$ values differ slightly from one sample to another, we have listed in Table 1 the average values of $E_{g}$ calculated with eqn (3). The average values of $\mathrm{E}_{\mathrm{g}}$ determined with eqn (2) are a little lower than those of eqn (3) (Table $\mathrm{S} 3$ in the $\mathrm{ESI}+$ ), but the trends are identical and our discussion of the $\mathrm{E}_{\mathrm{g}}$ values below does not depend on the model considered.

Non oriented Tilv oxide NWs

Oriented Tilv oxide NWs
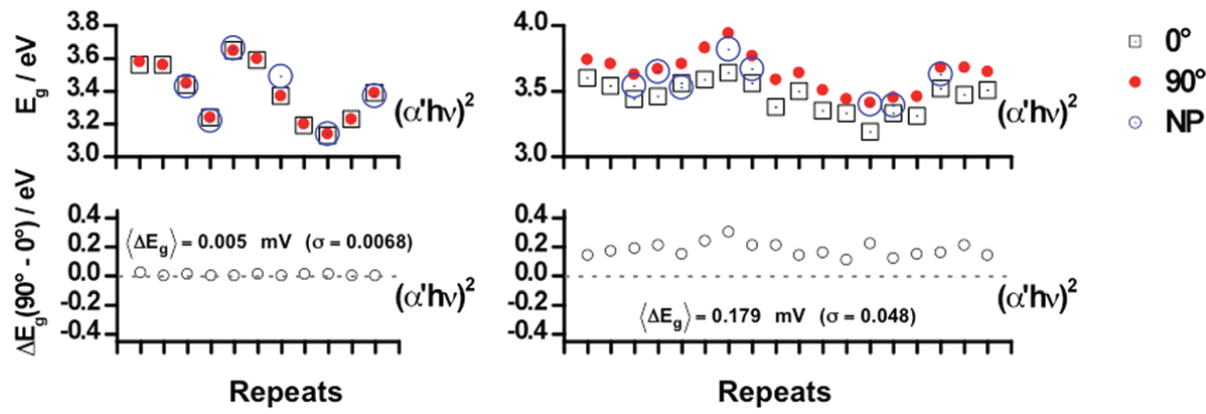

Fig. 3 Band gap energy values (top) determined from transmission spectra using eqn (2) for several Tilv oxide NWs samples prepared by DC or GIS and illuminated with $0^{\circ}$ or $90^{\circ}$ polarized or non-polarized (NP) light and (bottom) the corresponding $\triangle E g\left(90^{\circ}-0^{\circ}\right)$ values. 
When illuminated with non-polarized light, the electronic transition for the spherical $\mathrm{TiO}_{2} \mathrm{NPs}_{\text {(P25) }}$ was found to be indirect $(p=2)$ with an average value of $E_{g}$ of $3.05 \mathrm{eV}$ (Table 1), which is consistent with the literature. ${ }^{22,23}$ The electronic transition for the $\mathrm{ZnO} N W s$ was direct $(p=1 / 2)$ with an average value $\mathrm{E}_{\mathrm{g}}$ of $3.10 \mathrm{eV}$, also in agreement with the literature. ${ }^{24,25}$ In the case of $\mathrm{Ti}^{\mathrm{iV}}$ oxide NWs, we observed an $E_{g}$ of $3.38 \mathrm{eV}$ assuming a direct electronic transition $(p=1 / 2)$. This gap energy could be consistent with that of anatase, rutile or brookite ( $E_{g}$ ranges from 3.0 to $3.6 \mathrm{eV}$ for these polymorphs). ${ }^{26}$ If an indirect electronic transition was assumed $(p=2)$, the $E_{g}$ values were negative for most measurements, which is unphysical. However, the different polymorphs of $\mathrm{TiO}_{2}$ are reported to have an indirect band gap. ${ }^{26}$ Hence, the experimental band gap energy observed here could possibly also be due to the presence of multiple phases in the $\mathrm{Ti}^{\mathrm{IV}}$ oxide NWs which is analytically very difficulty accessible (see below).

\begin{tabular}{|c|c|c|c|c|c|c|c|}
\hline \multirow{2}{*}{\multicolumn{2}{|c|}{$z$}} & \multicolumn{6}{|c|}{$\left\langle E_{\mathrm{g}}\right\rangle \mathrm{eV}$} \\
\hline & & \multicolumn{2}{|c|}{ P25 NPs } & \multicolumn{2}{|c|}{ ZnO NWs } & \multicolumn{2}{|c|}{$\mathrm{Ti}^{\mathrm{IV}} \mathrm{NWs}$} \\
\hline Polarisation & $p$ & DC & GIS & DC & GIS & DC & GIS \\
\hline NP & $\begin{array}{l}1 / 2 \\
2\end{array}$ & 3.05 & 3.24 & 3.10 & 2.20 & 3.38 & 3.58 \\
\hline $90^{\circ}$ & $\begin{array}{l}1 / 2 \\
2\end{array}$ & 3.04 & 3.25 & 3.13 & 3.20 & 3.40 & 3.64 \\
\hline $0^{\circ}$ & $\begin{array}{l}1 / 2 \\
2\end{array}$ & 3.04 & 3.23 & 3.13 & 3.20 & 3.40 & 3.46 \\
\hline
\end{tabular}

Table 1 Summary of the average values of the apparent gap energy values (Eg) obtained using eqn (2) with $p=$ $1 / 2$ or $p=2$ for spherical $\mathrm{TiO}_{2} N \mathrm{NP}, \mathrm{ZnO} N W s$ and $\mathrm{Ti}^{\prime \prime}$ oxide NWs deposited by drop-casting (DC) or grazing incidence spraying (GIS) and illuminated with light polarized at $0^{\circ}$ or $90^{\circ}$ or non-polarized (NP) light.

In Fig. 3 and $S 18,+$ one observes that the $E_{g}$ values vary slightly among different repeats of deposits composed of the same aligned nano-objects. In addition to variations due to fitting of the spectra, as discussed in section III of the ESI, + a difference in the surface coverage $(\theta)$ leads to a shift in the band gap energy $E_{g}+f(\theta)$. Thus, a slight variability in the surface coverage from one sample to another would explain the observed distribution of $\mathrm{E}_{\mathrm{g}}$ values and these values should rather be considered as apparent band gap energies. However, as the polarized transmission spectra were measured in the same area for both polarization states, the differences in $\mathrm{E}_{\mathrm{g}}$ should be less sensitive to variations in the surface coverage. We therefore plotted the difference in $\mathrm{E}_{\mathrm{g}}$ determined from the transmission spectra with light polarized at $0^{\circ}$ and $90^{\circ}$ for each of the repeats (Fig. 3 and S19†). As should be expected for isotropic samples (see above), spherical TiO2 NPs, non-oriented ZnO NWs and non-oriented Tiv oxide NWs display similar $\mathrm{E}_{\mathrm{g}}$ values irrespective of the light polarization, and hence $\Delta \mathrm{Eg}\left(90^{\circ}-0^{\circ}\right) \approx 0 \mathrm{eV}$. Despite the fact that the transmittance of oriented $\mathrm{ZnO} N W s$ depends on the light polarization (probably because the dielectric constant is polarization-dependent), the band gap energy determined is independent of the polarization and $\Delta \mathrm{Eg}\left(90^{\circ}-0^{\circ}\right) \approx 0 \mathrm{eV}$. In contrast, all the oriented Tilv oxide NW samples show significantly different $\mathrm{E}_{\mathrm{g}}$ values for light polarized at $0^{\circ}$ and $90^{\circ}$ with $\Delta \mathrm{Eg}\left(90^{\circ}-0^{\circ}\right)>0 \mathrm{eV}$ in all cases. The average value of the band gap anisotropy $\Delta \operatorname{Eg}\left(90^{\circ}-0^{\circ}\right)$ is $0.17 \mathrm{eV}(\sigma=0.05 \mathrm{eV})$. Small differences in $\Delta \mathrm{Eg}\left(90^{\circ}-0^{\circ}\right)$ for different thin films of oriented $\mathrm{Ti}^{\mathrm{iV}}$ oxide NWs can be observed, which might arise from slight variations between the orientation of the polarization of the light and that of the orientation of NWs or from variations in the quality of the orientation over the illuminated area. Although the transmittance of non-polarized light does not fall between the transmittance of light polarized at $0^{\circ}$ and $90^{\circ}$, the apparent optical band gap energies obtained from unpolarized light are intermediate to those obtained from polarized light.

Interestingly the observed values of the optical gap of $\mathrm{Ti}^{\mathrm{iv}}$ oxide NWs seem to not agree with those of the three classic phases and unidirectional aligned Tilv oxide NWs deposits exhibit a polarization dependent difference in the band gap energies whereas unidirectional aligned $\mathrm{ZnO} \mathrm{NW}$ deposits do 
not. In order to rule out effects from compositional and structural variations within Tilv oxides NWs and $\mathrm{ZnO} \mathrm{NWs}$, further investigations were carried out.

From spherical P25 NPs, it is know that they are composed of ca. $80 \%$ anatase and $20 \%$ rutile with a high purity in titanium (>99.5\%). ${ }^{27}$ Fig. S20 shows the HRTEM and electronic diffraction patterns of the ZnO NWs. It can be seen that they present a distinct crystalline phase, e.g., wurtzite (Fig. S2OAt), but that each nanowire does not consist of a single crystallite (Fig. S2OB ${ }^{+}$). Several defects such as junctions between wires (Fig. S2OC+), amorphous regions, twinning planes and stacking faults (Fig. $\mathrm{S} 20 \mathrm{D}^{+}$) can be observed. These nano-objects thus display a poor crystalline quality.

On the contrary, the $\mathrm{Ti}^{\mathrm{IV}}$ oxide NWs are better crystallized (Fig. 4A-D) and the same electron diffraction pattern with the same orientation is observed along each nanowire (Fig. 4C). An interplanar distance which could be matched to the (001) planes $(d=0.951 \mathrm{~nm})$ and the $(200)$ or $(020)$ planes $(d=0.19 \mathrm{~nm})$ of anatase can be distinguished on the HRTEM image (Fig. 4A) and the FFT of the HRTEM image (Fig. 4B), respectively. However, the electron diffraction pattern corresponds to a rectangular in-plane lattice with approximate lattice parameters $\mathrm{a} \approx 20 \AA$ and $\mathrm{b} \approx 3.8 \AA$, which is not consistent with the data for anatase (see below).
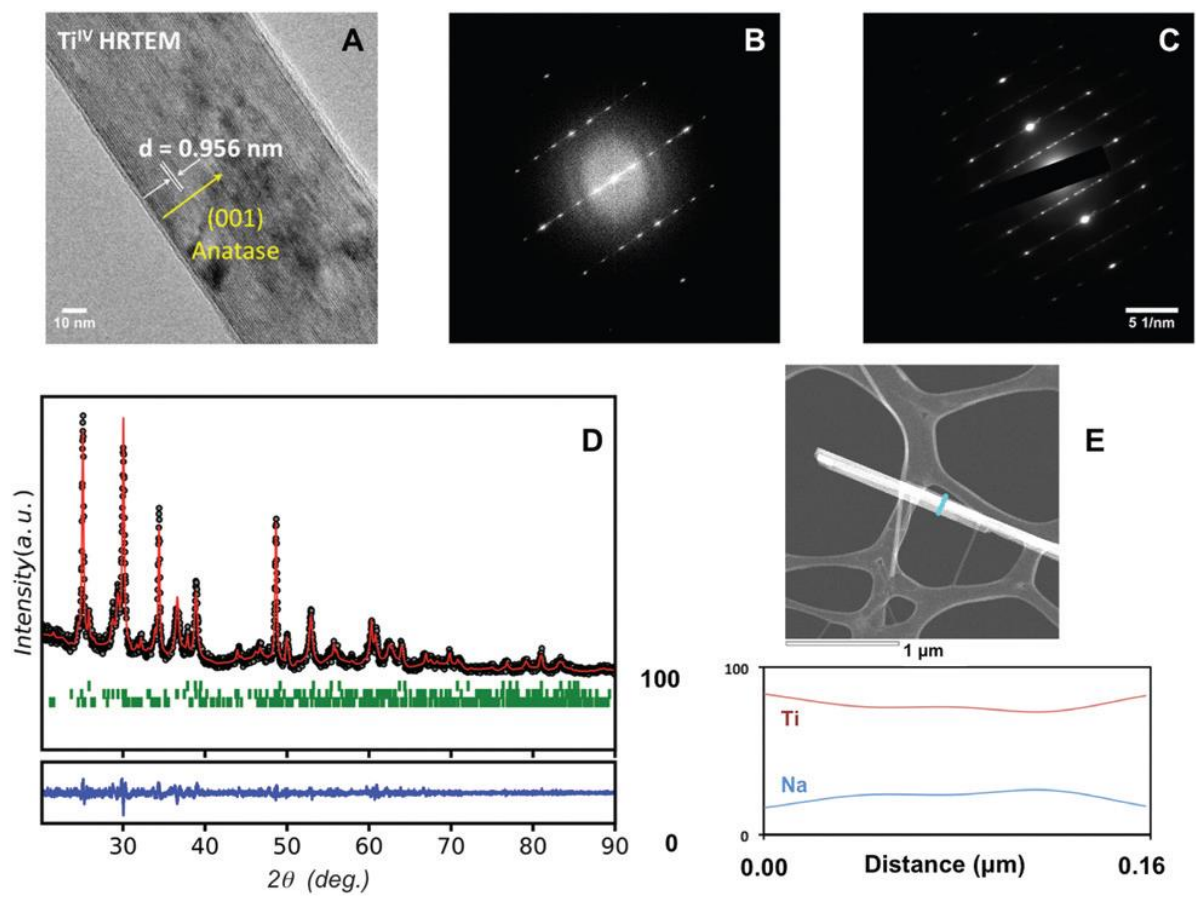

Fig. 4 (A) HRTEM image of TiV oxide NWs, (B) FFT of the HRTEM image and (C) electron diffraction pattern. (D) Powder X-ray diffraction pattern of the TilV oxide NWS. (E) Mapping of the amounts of Na and Ti by EDS-STEM along a $\mathrm{Ti}^{\prime V}$ oxide nanowire.

The powder X-ray diffraction (XRD) pattern (Fig. 4D) shows that the NWs are well-crystallized, but do not consist of a single phase. Indeed, three phases are present, namely $\mathrm{TiO}_{2}$ anatase (tetragonal, $\mathrm{a}=\mathrm{b}$ $=3.78 \AA, c=9.51 \AA$, PDF 00-021- 1272), $\beta \mathrm{TiO}_{2}$ (monoclinic, $a=12.20 \AA, b=3.74 \AA, c=6.53 \AA, \beta=$ 107.36 ${ }^{\circ}$, PDF 00-046-1238) and $\mathrm{Na}_{2} \mathrm{Ti}_{3} \mathrm{O}_{7}$ (monoclinic, $a=9.13 \AA, b=3.80 \AA, c=8.56 \AA, \beta=101.57^{\circ}$, PDF 04-015-7486). The presence of these phases as intermediate structures has already been reported in titanium oxide nanorods obtained by hydrothermal synthesis. ${ }^{28,29}$ It may be assumed that in our commercial sample the full transformation to anatase was not achieved. Unfortunately, Rietveld refinement of the XRD pattern could not be performed due to the anisotropy and texture of the NWs and thus the relative amounts of each phase could not be determined. 
It was also impossible to deduce from the XRD data if all the NWs have an identical composition and all consist of a mixture of these three phases, or if different NWs with different structures coexist. Nevertheless, considering the information provided, a rectangular in-plane arrangement was consistent with neither of the two monoclinic phases. Therefore, we performed a chemical analysis of the $\mathrm{Ti}^{\mathrm{iV}}$ oxide powder and a chemical mapping by energy dispersive X-Ray spectroscopy (EDS) using a scanning transmission electronic microscope (STEM). The chemical analysis showed that the powder contained of $6.5 \mathrm{wt} \% \mathrm{Na}$ and $47 \mathrm{wt} \% \mathrm{Ti}$, corresponding to a $\mathrm{Na} / \mathrm{Ti}$ weight ratio of 0.14 . The atomic ratio of $\mathrm{Na}$ to Ti was measured locally by EDS-STEM along single NWs (Fig. 4E and Fig. S21+) and found to be constant along the nanowires. The average atomic ratio $\mathrm{Na} / \mathrm{Ti}$ was 0.30 , which corresponds to a weight ratio of 0.14 , the same as the result obtained by chemical analysis. If one assumes that all the $\mathrm{Na}$ is crystallized in the $\mathrm{Na}_{2} \mathrm{Ti}_{3} \mathrm{O}_{7}$ phase and all the Ti in either $\mathrm{Na}_{2} \mathrm{Ti}_{3} \mathrm{O}_{7}$ or $\mathrm{TiO}_{2}$, the $\mathrm{Na}_{2} \mathrm{Ti}_{3} \mathrm{O}_{7}$ phase represents about 19.4 at\% of the NWs. Consequently, this information, derived on a macroscopic and a nanoscopic scale and corroborated by XRD data, indicates that $\mathrm{Na2Ti3O}$ and $\mathrm{TiO} 2$ phases are present and distributed within the NWs. Even if Ti exits in its +IV oxidation state in both $\mathrm{Na}_{2} \mathrm{Ti}_{3} \mathrm{OO}$ and $\mathrm{TiO}_{2}$, the nanowires cannot be considered to consist of pure $\mathrm{TiO}_{2}$ but rather of a mixed $\mathrm{Ti}^{\mathrm{iV}}$ oxide, which could be at the origin of our experimental results.

The most remarkable outcome of our study is the large difference in the apparent optical gap energy depending on the polarization of the incident light with respect to the orientation of the $\mathrm{Ti}^{\mathrm{iV}}$ oxide NWs. Note that this difference was only observed for aligned $\mathrm{Ti}^{\mathrm{iV}}$ oxide NWs and not for aligned $\mathrm{ZnO}$ NWs, although the anisotropic deposits of the two materials display similar degrees of orientation. Anisotropic gap energy values varying with the polarization of the incident light have already been measured in single crystals of anatase and rutile $\mathrm{TiO}_{2}$, but the difference was only a few tens of meV at low temperature, depending on the orientation of the light polarization with respect to the $\langle 001\rangle$ crystallographic axis. ${ }^{30}$ The difference we report here $\left(\Delta \mathrm{Eg}\left(90^{\circ}-0^{\circ}\right) \approx 170 \mathrm{meV}\right)$ is much higher and was measured at room temperature.

In the following, we discuss a series of potential reasons that could explain this striking observation:

- Quantum confinement of charge carriers: such an effect has been previously reported for semiconducting NWs of $4-5 \mathrm{~nm}$ diameter. ${ }^{31,32}$ However, the large diameter of the Tilv oxide NWs is not consistent with this type of quantum confinement because it is much larger than the exciton Bohr radius.

- Measurement performed on sub-monolayer samples: using the model developed in the ESI (eqn (14) ${ }^{\dagger}$ ), the variations in $E_{g}$, which might be due to the limited coverage, could be of the same order of magnitude as the measured anisotropy. However, this explanation unlikely because the difference in Eg for the two polarizations was only observed in the oriented $\mathrm{Ti}^{\mathrm{iV}}$ oxide NW samples, despite the fact that the density of the nanowires was quite similar in oriented and non-oriented $\mathrm{Ti}^{\mathrm{IV}}$ oxide NW samples (Fig. S22t). Moreover, if the anisotropy in Eg were to depend solely on the anisotropic architecture of the sample and not on the intrinsic properties of the $\mathrm{Ti}^{\mathrm{iV}}$ oxide NWs, the same effect should be observed in aligned ZnO NW samples, which display a similar surface coverage and orientation as the $\mathrm{Ti}^{\mathrm{i}} \mathrm{v}$ oxide NW samples, but this was not the case.

- Quantum wells: ${ }^{33,34}$ a quantum well is a potential well in which an exciton is confined and occurs if the dimension of the quantum well is comparable to or smaller than the de Broglie wavelength of the exciton. Since it appears that the Tilv oxide NWs consist of several different titanium oxide semiconductor phases, one might assume that the typical sizes of the different crystallographic phases satisfy the required conditions for quantum wells.

None of these hypotheses above provides a reasonable and straightforward explanation for the huge anisotropy that is experimentally observed. Further investigations on the exact crystallographic structure of the $\mathrm{Ti}^{\mathrm{iV}}$ oxide NWs, the calculation of the electronic band diagram or photoluminescence and photoluminescence excitation spectroscopy performed on single objects may help to clarify the situation but are way out of the scope of the present manuscript. 


\section{Conclusions}

In conclusion, thin film deposits of highly oriented $\mathrm{ZnO}$ and $\mathrm{Ti}^{\mathrm{iv}}$ oxide nanowires were prepared by grazing incidence spraying (GIS) and compared to non-oriented thin films of the same nano-objects prepared by drop casting (DC) and to thin films of isotropic $\mathrm{TiO}_{2}$ nanoparticles. The transmission spectra of the non-oriented and the oriented thin films were measured on a macroscopic scale using non-polarized light and light polarized parallel and perpendicular to the long axis of the NWs. The apparent energy of the optical gaps $\left(\mathrm{E}_{\mathrm{g}}\right)$ was determined in each case and no differences were observed as a function of the light polarization except for the aligned TiV oxide NWs, which displayed a surprisingly large difference of more than $100 \mathrm{meV}$ between the two polarizations at room temperature.

\section{Conflicts of interest}

There are no conflicts to declare.

\section{Acknowledgements}

We would like to thank Prof. S. Suzer for the XPS measurements, Dr Olivier Félix, Dr Benoît Heinrich and Dr Patrick Kekicheff for helpful discussions and ANR-11LABX-0058-NIE for financial support.

\section{References}

1 M. S. Dresselhaus, G. Chen, M. Y. Tang, R. Yang, H. Lee, D. Wang, Z. Ren, J.-P. Fleurial and P. Gogna, Adv. Mater., 2007, 19, 1043.

2 Y. Li, F. Qian, J. Xiang and C. M. Lieber, Mater. Today, 2006, 9, 18.

3 J.-L. Wang, M. Hassan, J.-W. Liu and S.-H. Yu, Adv. Mater., 2018, 30, 1803430.

4 N. A. C. Laha and S. Triguerosb, Sci. Technol. Adv. Mater., 2019, 20, 225.

5 G. Wang, H. Wang, Y. Ling, Y. Tang, X. Yang, R. C. Fitzmorris, C. Wang, J. Z. Zhang and Y. Li, Nano Lett., 2011, 11, 3026.

6 M. Law, J. Goldberger and P. Yang, Annu. Rev. Mater. Res., 2004, 34, 83.

7 J. Wang, M. S. Gudiksen, X. Duan, Y. Cui and C. M. Lieber, Science, 2001, 293, 1455.

8 F. Vouilloz, D. Y. Oberli, M.-A. Dupertuis, A. Gustafsson, F. Reinhardt and E. Kapon, Phys. Rev. B: Condens. Matter Mater. Phys., 1998, 57, 12378.

9 U. Bockelmann and G. Bastard, Europhys. Lett., 1991, 15, 215.

10 J.-W. Liu, H.-W. Liang and S.-H. Yu, Chem. Rev., 2012, 112, 4770.

11 H. Hu, S. Wang, X. Feng, M. Pauly, G. Decher and Y. Long, Chem. Soc. Rev., 2020, 49, 509.

12 (a) K. B. Blodgett, J. Am. Chem. Soc., 1934, 56, 495; (b) K. Ariga, Y. Yamauchi, T. Mori and J. P. Hill, Adv. Mater., 2013, 25, 6477.

13 S. Sekar, V. Lemaire, H. Hu, G. Decher and M. Pauly, Faraday Discuss., 2016, 191, 373.

14 G. Decher, Science, 1997, 277, 1232.

15 H. Hu, M. Pauly, O. Felix and G. Decher, Nanoscale, 2017, 9, 1307.

16 P. T. Probst, S. Sekar, T. A. F. König, P. Formanek, G. Decher, A. Fery and M. Pauly, ACS Appl. Mater. Interfaces, 2018, 10, 3046.

17 R. Blell, X. Lin, T. Lindström, M. Ankerfors, M. Pauly, O. Felix and G. Decher, ACS Nano, 2017, 11, 84.

18 G. Ladam, P. Schaad, J. C. Voegel, P. Schaaf, G. Decher and F. Cuisinier, Langmuir, 2000, 16, 1249; A. C. Santos, P. Pattekari, S. Jesus, F. Veiga, Y. Lvov and A. J. Ribeiro, ACS Appl. Mater. Interfaces, 2015, 7, 11972.

19 X. Zhao, C. Zhou, Y. Lvov and M. Liu, Small, 2019, 15, 1900357.

20 R. Rezakhaniha, A. Agianniotis, J. T. C. Schrauwen, A. Griffa, D. Sage, C. V. C. Bouten, F. N. Vosse and M. Unser, Biomech. Model. Mechanobiol., 2012, 11, 461; C. A. Schneider, W. S. Rasband and K. W. Eliceiri, Nat. Methods, 2012, 9, 671; M. D. Abramoff, P. J. Magalhaes and S. J. Ram, Biophotonics Int., 2004, 11, 36. 
21 R. López and R. Gómez, J. Sol-Gel Sci. Technol., 2012, 61, 1.

22 A. A. Valeeva, E. A. Kozlova, A. S. Vokhmintsev, R. V. Kamalov, I. B. Dorosheva, A. A. Saraev, I. A. Weinstein and A. A. Rempel, Sci. Rep., 2018, 8, 9607.

23 J. F. Guayaquil-Soza, B. Serrano-Rosales, P. J. Valadés-Pelayo and J. de Lasa, Appl. Catal. B, 2017, $211,337$.

24 A. H. Hammad, M. Sh. Abdel-wahab, S. Vattamkandathil and A. R. Ansari, Physica B: Condens. Matter, 2018, 540, 1.

25 A. Kaphle, M. F. Borunda and P. Hari, Mater. Sci. Semicond. Process., 2018, 84, 131.

26 D. Reyes-coronado, G. Rodríguez-Gattorno, M. E. Espinosa-Pesqueira, C. Cab, R. de Coss and G. Oskam, Nanotechnology, 2008, 19, 145605.

27 D. Martel, A. Guerra, P. Turek, J. Weiss and B. Vileno, J. Colloid Interface Sci., 2016, 467, 300.

28 S. Pavasupree, Y. Suzuki, S. Yoshikawa and R. Kawahata, J. Solid State Chem., 2005, 178, 3110.

29 Y. V. Kolen'ko, K. A. Kovnir, A. I. Gavrilov, A. V. Garshev, J. Frantti, O. I. Lebedev, B. R. Churagulov, G. Van Tendeloo and M. Yoshimura, J. Phys. Chem. B, 2006, 110, 4030.

30 H. Tang, H. Berger, P. E. Schmid and F. Lévy, Solid State Commun., 1994, 92, 267.

31 J. D. Holmes, K. P. Johnston, R. C. Doty and B. A. Korgel, Science, 2000, 287, 1471.

32 Q. Li and R. Jin, Nanotechnol. Rev., 2017, 6, 601.

33 D. Plumwongrot, T. Maruyama, A. Haque, H. Yagi, K. Miura, Y. Nishimoto and S. Arai, Jpn. J. Appl. Phys., 2008, 47, 3735.

34 W. I. Park, G.-C. Yi, M. Kim and S. J. Pennycook, Adv. Mater., 2003, 15, 526. 